Original Research Article

\title{
Evaluation of prescription pattern of antibiotics for surgical prophylaxis in secondary care hospital
}

\author{
Devesh Kumar Joshi*, Mohd Rizwan, Preeti Kothiyal, Yogesh Joshi
}

Department of Pharmaceutical sciences, Shri Guru Ram Rai Institute of Technology and Science (SGRRITS), Patel Nagar, Dehradun, Uttarakhand, India

Received: 27 May 2017

Revised: 24 June 2017

Accepted: 27 June 2017

*Correspondence to: Dr. Devesh Kumar Joshi, Email: deveshkumarjoshi@ gmail.com

Copyright: (C) the author(s), publisher and licensee Medip Academy. This is an openaccess article distributed under the terms of the Creative Commons Attribution NonCommercial License, which permits unrestricted noncommercial use, distribution, and reproduction in any medium, provided the original work is properly cited.

\begin{abstract}
Background: Antibiotic prophylaxis is the prevention and in incidence of surgical site infection. This study evaluates the rational use of antibiotics prophylaxis prior to surgery amongst hospitalized patients. Objectives of the study were to investigate the utilization and evaluation pattern of antibiotics for surgical prophylaxis in surgery department.

Methods: A prospective observational study was conducted on 100 patients receiving antibiotics in the Department of Surgery of Brijesh Hospital Ramnagar (Nainital) Uttarakhand. Patient undergoing antibiotic prophylaxis treatment were included in the study, exclusion of those patients who had age less than 18, patients with psychiatric disease and those patients not willing to sign on inform consent form.

Results: The result observed in 100 patients follow up 8 weeks and evaluate the appropriate use of prophylaxis of antibiotics majority of patients were age group 18-30 years, followed by 41-50 years, 51-60 years, majority were reported in female patients than male, higher utilization of cephalosporins were commonly prescribed due to their relatively lower toxicity and broader spectrum activity and broader coverage of organism for several serious gram negative infection 30 $(30 \%)$ patients were prescribed penicillin with aminoglycosides, 10 (10\%) patients were prescribed with nitroimidazole antibiotics.

Conclusions: The overall scenario of antibiotic usage in a Hospital was as per standard recommendations and all the antibiotics used were according to their standard adult and titrated doses and frequencies. In this study we found that Cephalosporines, Penicillins, Aminoglycosides and Nitroimidazole were mostly used classes of drug. Adverse Drug Reactions were minor and well managed.
\end{abstract}

Keywords: Antibiotic, Adverse drug reaction, Prophylaxis, Surgical site infection

\section{INTRODUCTION}

Drug utilization evaluation (DUE) is a system ongoing, systematic, criteria-based evaluation of drug usage that makes sure that medicines are used in an appropriate way (at the individual patient level). If therapy is seems to be inappropriate, interventions from providers or patients will be necessary to optimize drug therapy, a DUE is drug or disease specific and can be arranged in such a way that it will assess the actual process of prescribing, dispensing or administering a drug (indications, dose, drug interactions, etc.), DUE is the same as drug utilization review (DUR) and terms are used synonymously. ${ }^{1}$
WHO defines drug utilization as "the marketing, distribution, prescription and use of drug in a society with special emphasis on resulting medical, social and economic consequences" The aim of drug utilization research is to facilitate rational use of drugs in the populations. $^{2}$ Without knowledge, how drugs are being prescribed and used it is complicated to suggest measure to change prescribing habits for better. ${ }^{3}$

A increasing number of pharmaceutical products are available on the world market and there has been an increase both in the consumption of the drugs and in 
expenses done on them, inspite of this, many people throughout the world cannot get the drugs they require. ${ }^{4}$

There are also many people who have access to drugs but do not get the correct drug in the right dosage when they require, irrational prescription of drug is of common occurrence in clinical practice, important reason being lack of knowledge about drug, and unethical drug promotion. ${ }^{5}$

The defined daily dose (DDD) is globally accepted technical unit in drug utilization studies, which reckones the average maintenance dose per day of a drug for its main manifestation in adult it must be emphasized that DDD is a unit of measurement and does not corelate with the prescribed daily dose, the dose of individual patient will however vary from the DDD as they are dependent upon pharmacokinetic and individual characterstics eg-(age and weight) drug utilization studies merely calculate the exact amount of the drug consume by or recommended to the patients, this give us upper or lower estimation of real drug use. $^{6}$

Drug Utilization Evaluation (DUE), of Antibiotics use in Surgical Prophylaxis is a study of Utilization and Evaluation of Antibiotics use in surgery, surgical site infection is chief complication of surgical procedure, it represents a significant burden in terms of patient morbidity, mortality and hospital costs, patient who developed SSI (Surgical Site Infection) are up to $60 \%$ more likely to spend time in the intensive care unit, five times more likely to readmitted to hospital and twice as likely to die as compared to patients without SSI Surgical antibiotic prophylaxis is administration of short acting antimicrobial agent prior to surgery to prevent SSI. ${ }^{7}$

From more than 30 years, prophylactic use of antibiotics in hospitals before surgery showed a decrease in post operative infection rate, on enquiring the time of administration it was confirmed that the use of antibiotic two hours prior to surgery would reduce the chance of infection, however, appropriate use would reduce the chance of resistance development, further the effect of prophylactic antibiotic use other than to prevent surgical infection was found to be in nosocomial pneumonia where it reduce the incidence of pneumonia but it had no effect on mortality this occurred because antibiotic resistance bacteria colonized some patient after were difficult to treat. $^{8}$

Rational Use of Antibiotics antibiotics are most commonly prescribed drug their therapeutic uses increasing the bacterial resistance, irrational use of antibiotics is a common problem which leads to antibiotic resistance and adverse reactions, it is necessary to take several steps to improve the appropriate use of antibiotic, appropriate antibiotic selection can reduce the both cost and resistance to the patient. ${ }^{9}$

\section{METHODS}

A prospective observational study was conducted in the Department of Surgery of Brijesh Hospital Ramnagar (Nainital) Uttarakhand. The study was designed to be a Prospective Observational Study of four months. The participants enrolled in the study involved in patients coming to the hospital, only after filling a properly written informed consent. Basic demographic information and details of the prescribed antibiotics and their prescribing patterns, diseases for which they were indicated, dosage form of antibiotics and whether mono or multi-therapy is used, were documented in all patients. In view of collecting the aforementioned details, the data from in patients was obtained every day from the clinical assessment records, including medical records, patient record file, and other relevant information sources as documented, including laboratory investigations. Descriptive analysis was carried out for the data obtained.

\section{Study design}

It was a Prospective observational study conducted in the Inpatient department of surgery ward, of Brijesh Hospital Ramnagar. All subjects were receiving antimicrobials were enrolled for the study based on the following inclusion and exclusion criteria.

\section{Inclusion criteria}

- $\quad$ Patient visited to IPD Surgery department.

- $\quad$ Patient more than 18 year of age.

- Patient able to understand provide inform consent form.

- $\quad$ Patient of either gender.

\section{Exclusion criteria}

- $\quad$ Patient not willing to sign on Inform consent form.

- Patient with Psychiatric disease.

- $\quad$ Patient with less than 18 year of age.

The study was conducted for a duration of six months i.e. September to February.

All necessary and relevant were collected from Patient record file, treatment charts, Patient history records verbal communication with the patients.

\section{Data collection}

The data was collected in suitably designed CRF, which contain demographics, disease, lab data and therapeutic chart of the patient.

\section{Biostatistical analysis}

The data has been analysed by using descriptive statistics using Microsoft Excel as a software. 
The aim of this study was to investigate the utilization and evaluation pattern of antibiotics for surgical prophylaxis in surgery department in Brijesh Hospital Ramnagar.

\section{Objectives of study}

- To study the Incidence of surgical site infection.

- To evaluate the prescription pattern of antibiotics.

- To evaluate the rational antibiotic use.

- To assess the infection developed.

\section{RESULTS}

\section{According to disease pattern of the patients}

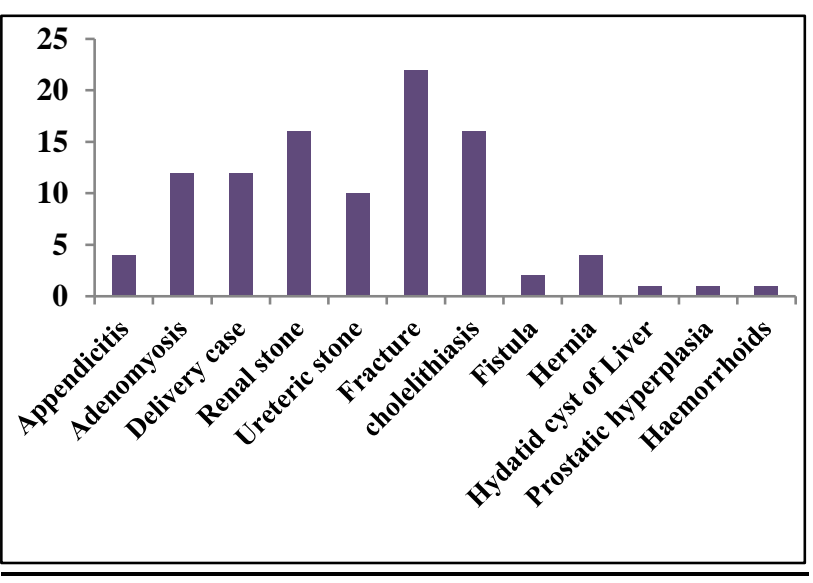

Figure 1: Disease pattern reported.

The common reason for admission in surgery ward was 22 $(22 \%)$ had fracture, 16 (16\%) patients had cholelithiasis,
$16(16 \%)$ patients had renal stone and $12(12 \%)$ patients had adenomyosis, $11(11 \%)$ cases was of delivery, 10 $(10 \%)$ was had ureteric stone, $4(4 \%)$ patients had appendicitis and $4(4 \%)$ patients with hernia, $2(2 \%)$ patients of fistula, $1(1 \%)$ of Haemorrhoids and $1(1 \%)$ was of hydatid cyst of liver (Figure 1).

Table 1: Demographics characteristics.

\begin{tabular}{|c|c|c|c|}
\hline Variables & & $\begin{array}{l}\text { No. of } \\
\text { participants }\end{array}$ & Percentage \\
\hline \multirow{2}{*}{ Gender } & Male & 45 & 45 \\
\hline & Female & 55 & 55 \\
\hline \multirow{7}{*}{ Age (years) } & $18-30$ & 47 & 47 \\
\hline & $31-40$ & 18 & 18 \\
\hline & $41-50$ & 18 & 18 \\
\hline & $51-60$ & 7 & 7 \\
\hline & $61-70$ & 7 & 7 \\
\hline & $71-80$ & 2 & 2 \\
\hline & $81-90$ & 1 & 1 \\
\hline \multirow{5}{*}{$\begin{array}{l}\text { Occupational } \\
\text { status }\end{array}$} & $\begin{array}{l}\text { House } \\
\text { wife }\end{array}$ & 41 & 41 \\
\hline & $\begin{array}{l}\text { In } \\
\text { organized } \\
\text { sector }\end{array}$ & 26 & 26 \\
\hline & Student & 17 & 17 \\
\hline & Retired & 8 & 8 \\
\hline & Business & 8 & 8 \\
\hline \multirow{4}{*}{$\begin{array}{l}\text { Educational } \\
\text { status }\end{array}$} & Illiterate & 9 & 9 \\
\hline & SSC & 40 & 40 \\
\hline & HSC & 24 & 24 \\
\hline & UG & 27 & 27 \\
\hline \multirow{2}{*}{ Marital status } & Married & 80 & 80 \\
\hline & Unmarried & 20 & 20 \\
\hline
\end{tabular}

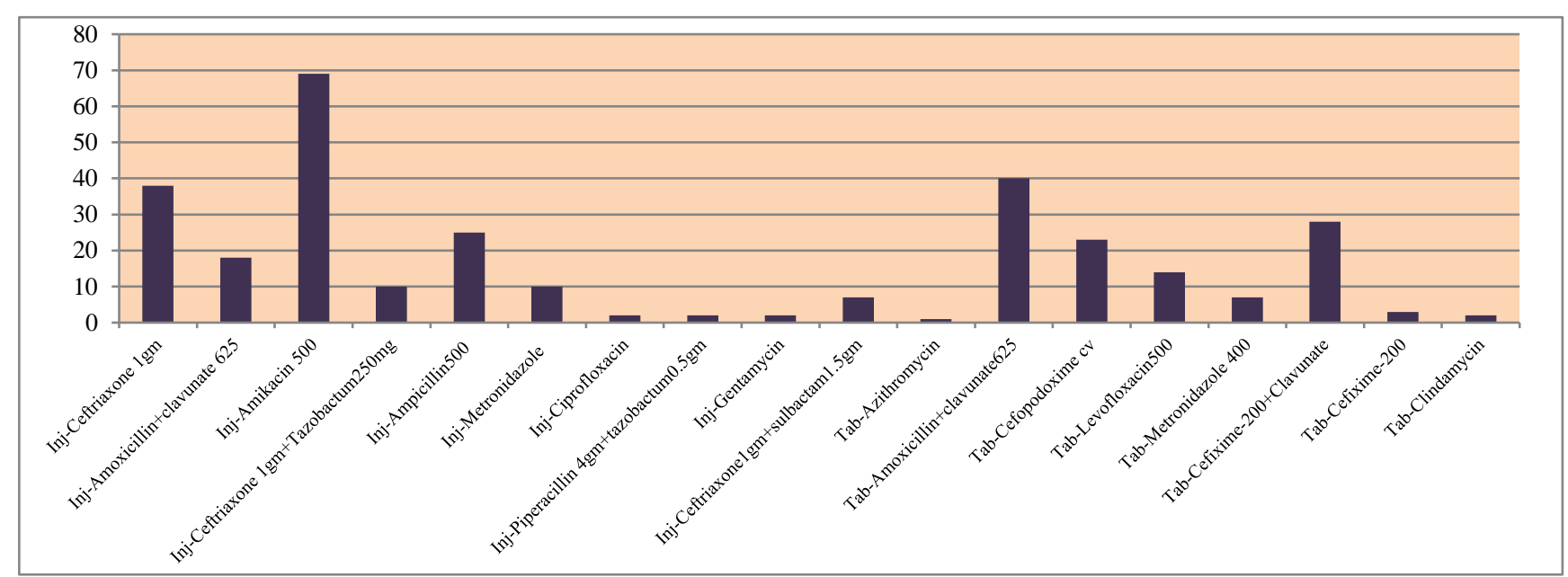

Figure 2: The distribution of antibiotics.

Distribution of antibiotics in study population
In this study the most commonly used intravenous antibiotic were the Inj-ceftriaxone 38 (38\%), which is 
accounted of 38 patients out of total 100 patients and in 18 (18\%) Inj-amoxicillin+ clavulanicacid were used, in 69 (69\%) Inj-amikacin, Inj ceftriaxone+ sulbactum 7 (7\%), Inj- ceftriaxone+ tazobactum 10 (10\%), Inj-ampicillin 25 (25\%), Inj-metronidazole $10(10 \%)$, Inj-ciprofloxacin 2 (2\%), Inj-gentamycin $2(2 \%)$ in this study the most commonly used oral antibiotic were Tab amoxicillin+ clavulanicacid $40(40 \%)$, in $28(28 \%)$ followed by Tabcefixime+ clavulanic acid, Tab-Cefixime 3 (3\%), TabCefopodoxime clavulanicacid 23 (23\%), Tab-levofloxacin 14 (14\%), Tab azithromycin 1 (1\%), Tab-clinadamycin 2 (2\%) shown in Figure 2.

\section{Distribution of antibiotics according to class}

Distribution according to class $86(86 \%)$ patients were prescribed with cephalosporins, followed by $15(15 \%)$ Fluoroquinolones, $64 \quad(64 \%)$ followed by aminoglycosides, 53 (53\%) followed by ampicillin and 19 (19\%) patients were prescribed with antiameobiasis shown in Figure 3.

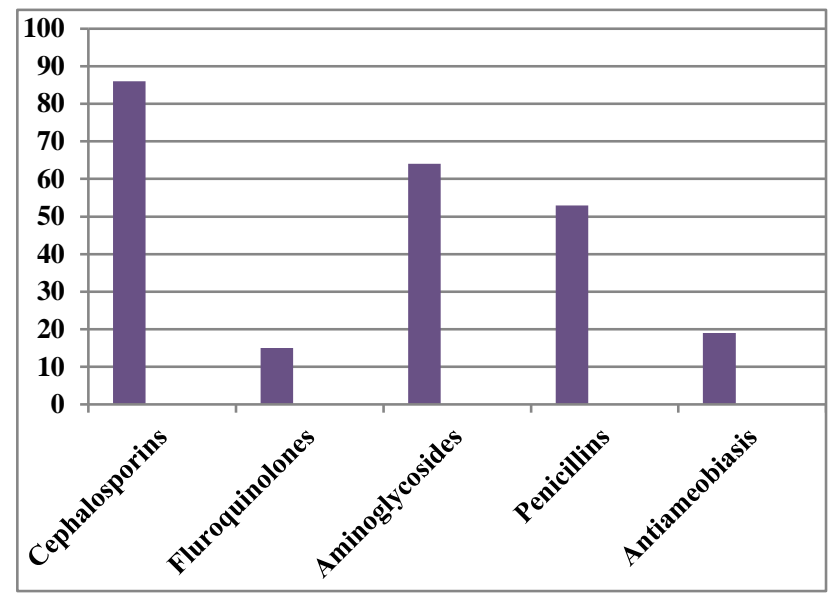

Figure 3: The distribution of antibiotics according to class.

Pattern of use of antibiotics in surgery patients during study period

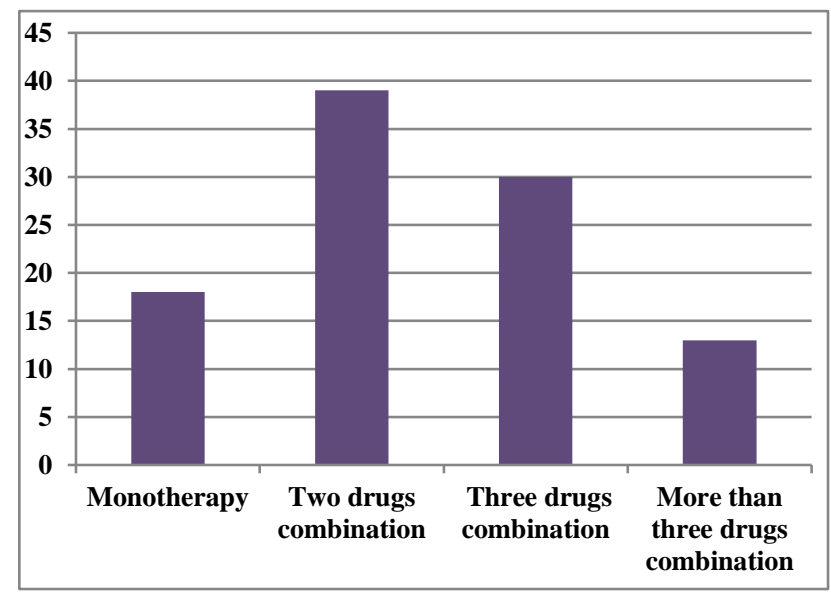

Figure 4: The pattern uses of antibiotics.
Out of 100 prescriptions included for the study, 39 (39\%) prescriptions had two drugs therapy, 30 (30\%) prescriptions had three antibiotic drugs combinations, 18 (18\%) prescriptions had antibiotic monotherapy, 13 (13\%) prescriptions were more than three antibiotic drug combinations shown in Figure 4.

\section{Pattern of developing infection}

Out of 100 participants were involved in $36(36 \%)$ patients developed surgical site infection, remaining 64 (64\%) patients were not developed any infection shown in Figure 5.

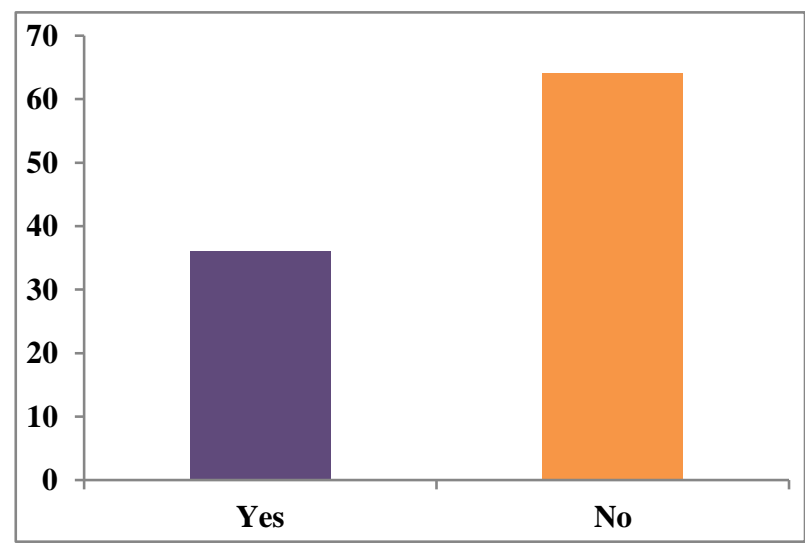

Figure 5: The pattern of developing infection.

\section{Dosage forms used in the study}

In our study, we also taken an account different antibiotic dosage forms used by the patient population Out of 100 prescriptions included for the study, to most of the patients $100(100 \%)$ antibiotics given by intravenous route and to $90(90 \%)$ patients antibiotic given by oral route shown in Figure 6.

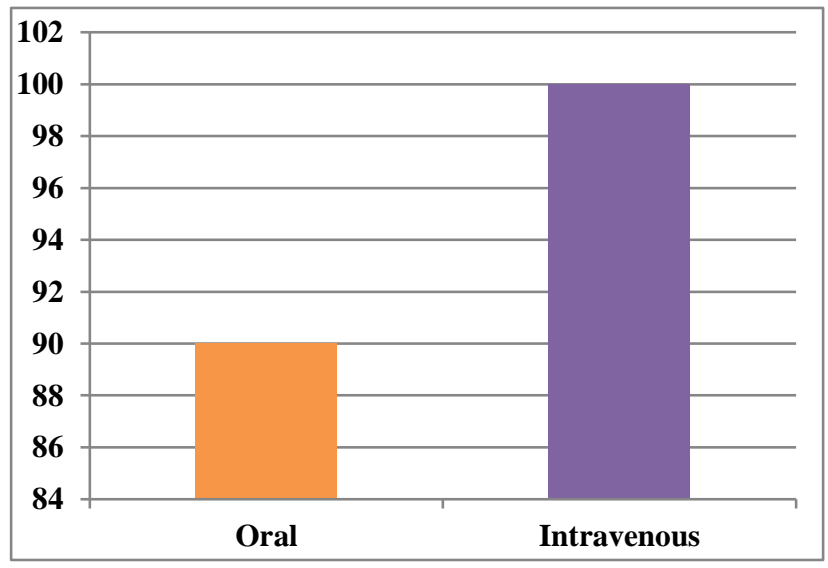

Figure 6: The dosage form of antibiotics.

\section{Duration of treatment}

A total 100 patients were involved in this study in which found that $52(52 \%)$ patient had duration of treatment 5 
days and less, rest of the patients had more than 5 days shown in Figure 7.

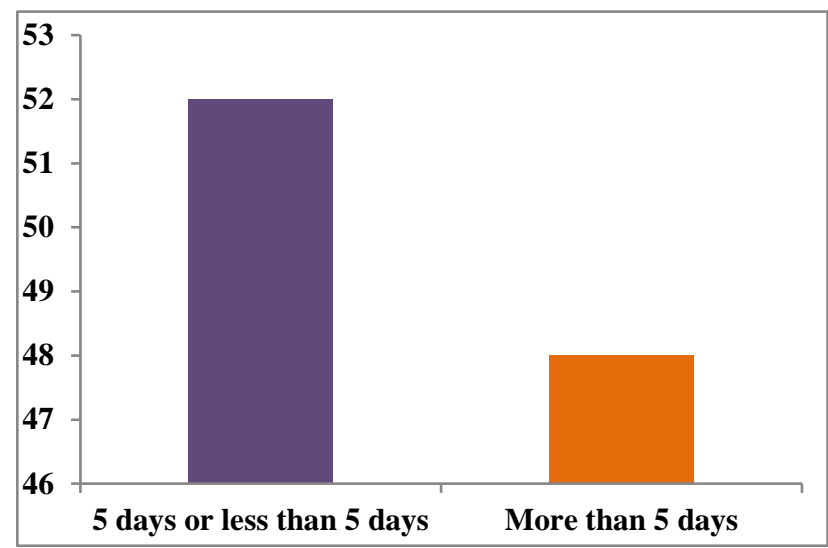

Figure 7: The duration of treatment.

\section{Prescribing pattern of antibiotic}

100 prescriptions were involve in study in which to the 88 (88\%) drug were prescribed by brand name and to the remaining $12(12 \%)$ patient drug were prescribed by generic name shown in Figure 8.

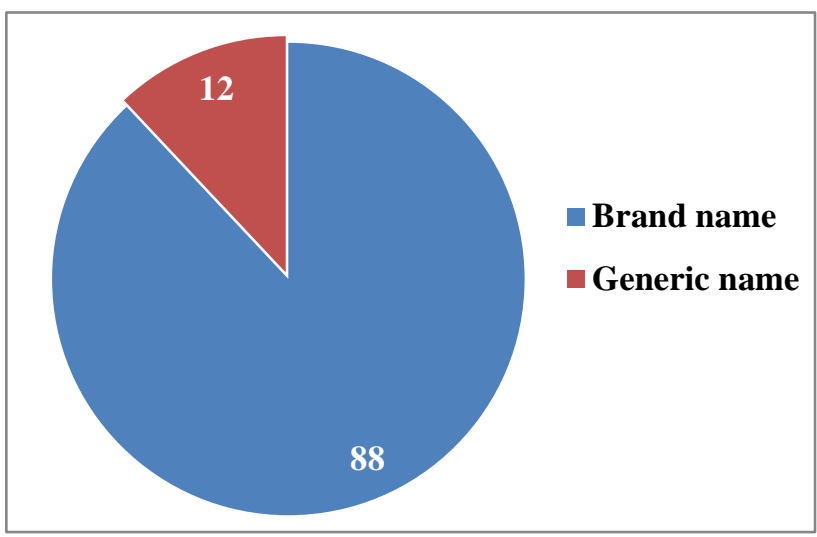

Figure 8: Pattern of antibiotics.

\section{Total number of drugs per encounter}

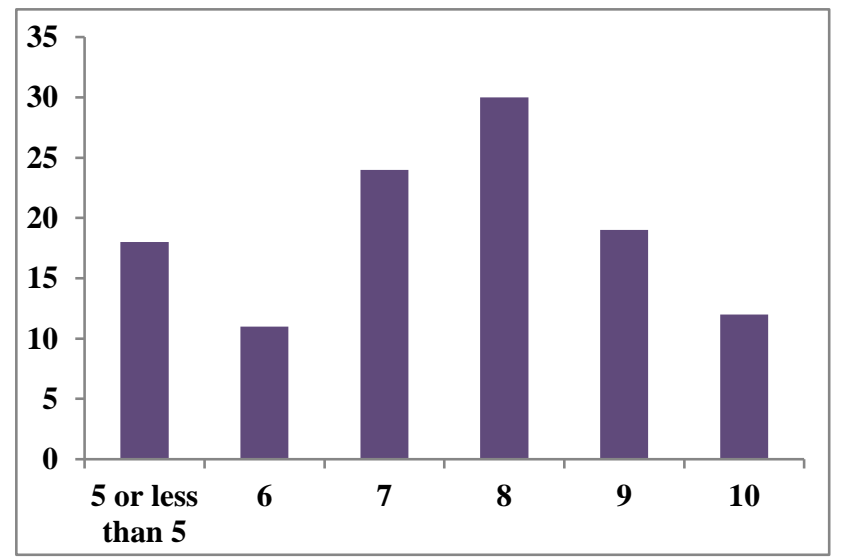

Figure 9: The no. of antibiotics per encounter.
Out of 100 patients the average number of drugs per encounter is 7.85 in our study total number of antibiotics drugs encounter shown in Figure 9.

\section{Antibiotics Prescribing Pattern according to essential drugs list}

Total 100 prescriptions were involved in study in which observed that in $86 \%$ prescriptions had antimicrobial agents that were included in the WHO Essential drug list and only $14 \%$ of prescriptions contained drugs that were not included in the WHO Essential drug list. $100 \%$ prescription had antimicrobial agent that were included in National list of essential medicine shown in Figure 10.

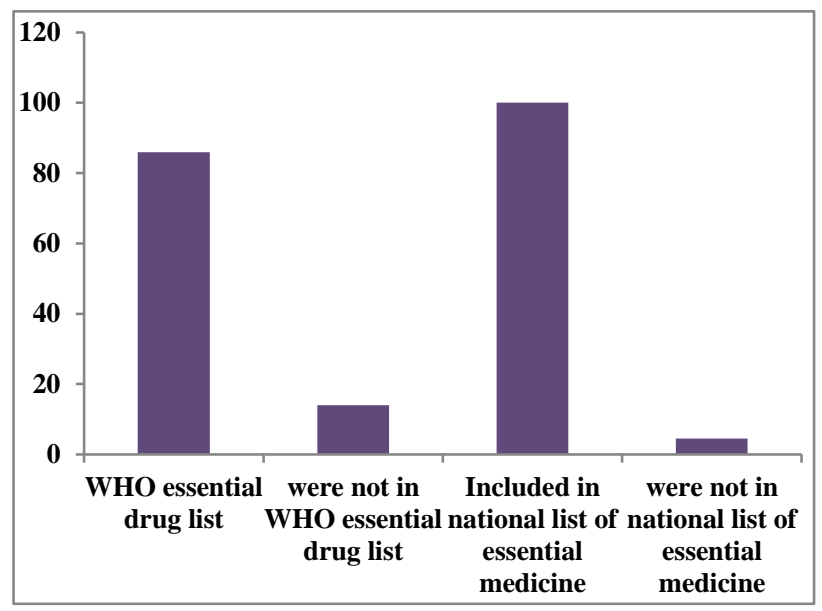

Figure 10: Antibiotics prescribing pattern according to essential drug list.

\section{DISCUSSION}

Monitoring of systems and interventions are useful in improving the quality of healthcare system. This is especially relevant for appraisal of antibiotic utilization prescription. Prescriber's world worldwide running out of antibiotic option.

As the antibiotics drug resistance is on the raise there is a need for taking steps to promote rational antibiotics use. It is necessary to take action improve prescribing habits in order to reduce the unnecessary usage of antibiotics thus enhance rational antibiotic use.

The data was subjected to descriptive analysis using Microsoft Excel. Utilization of different classes of drugs as well as individual drugs was analyzed and presented as percentage.

Out of 100 patients, patient disseminated according to gender. Female were relatively higher than male as they were $55(55 \%)$, then male as they were $45(45 \%)$, compared to another study Napolitano F, Teresa M conducted at Department of Experimental Medicine, Second University of Naples, Naples, Italy in which out of 404 patients $44.3 \%$ were males and $55.7 \%$ were females, 
but differ from study Venkateswarlu B, et al. conducted at Malla Reddy Institute of Pharmaceutical Sciences, Secuderabad, Telangana, India in which female were 108 $(53 \%)$ were males and $94(47 \%)$ were females. ${ }^{10,11}$

In our study most of the hospitalization were due to fracture $22 \%$, cholelithiasis $16 \%, 16 \%$ patients had renal stone and adenomyosis $12 \%$ this is because study center is referred hospital a large number of cases indicate insufficient healthcare facilities at the region furthermore, excess cares of renal stone adenomyosis, cholelithiasis might be due to lack of awareness to get early help as well, poverty may be a reason of late arrival of the cases.

But differ from Venkateswarlu B, et al, conducted at Malla Reddy Institute of Pharmaceutical Sciences, Secuderabad, Telangana, India study in which most commonly sugery done was Hernia 29 (14.5\%), Appendicitis 28 (14\%), Cholelithiasis $6(3 \%)$ and renal calculi $5(2.5 \%)$, Fistula 5 $(2.5 \%){ }^{11}$

In our study according to age categorization out of 100 patients 47 (47\%) patients had age of 18-30 years, 18 (18\%) patients had an age of 31-40 years, 18 (18\%) patients had an age of 41-50, $7(7 \%)$ patients had an age of 51-60 years, 7 (7\%) patients had an age of 61-70 years, 2 patients had an age of 71-80 years and $1(1 \%)$ patient had an age of 81-90. We observed that majority of cases in this sample were between the age group 18 to 40 Venkateswarlu B, et al, conducted at Malla Reddy Institute of Pharmaceutical Sciences, Secuderabad, Telangana, India and Brethis CS, et al, conducted at Mahavir Institute of Medical Sciences, Hydrebad India observed the same age group in their respective regions. ${ }^{11,12}$ This is usual trends as the fecund age group that is actively involved in socioeconomic activity, making them susceptible to disease which may further needs surgical intervention.

In our study most of them were done primary education 40 (40\%), 24 (24\%) participants have done secondary education and 27 (27\%) participants have done UG and 9 (9\%) participant never received any education. Similar to Venkateswarlu B, et al, conducted at Malla Reddy Institute of Pharmaceutical Sciences, Secuderabad, Telangana, India observed that $30 \%$ were done secondary education, $15 \%$ had received primary education, $10 \%$ had done higher education. ${ }^{11}$

In the study population polypharmacy was ascertained as drugs per prescription were high 7.85 , which contain antimicrobial agents in the most cases followed by NSAIDS, PPI and other drugs were given. Bhansali NB, et al, conducted at department of pharmacology, M P Shah Medical College, Jamnagar observed polypharmacy in their respective regions in which the average no of antibiotics use was $9.2 .^{13}$

The average number of drug per prescription is a valuable indicator of polypharmacy, it is recommended that the number of drugs per prescription should be kept as low as possible to minimize the rise of drug interaction, adverse drug reaction.

In our study $88 \%$ branded drugs were preferred by the surgeons and frequency of drugs were disproportionate compared to another study conducted by Bhansali NB. et al, conducted at department of pharmacology, M P Shah Medical College, Jamnagar in which to the $48.57 \%$ patient drugs prescribed by generic name and to the $51.43 \%$ patients drug prescribed by brand name. ${ }^{13}$

In the study population polypharmacy was ascertained as drugs per prescription were high 7.85 , which contain antimicrobial agents in the most cases followed by NSAIDS, PPI and other drugs were given. Bhansali NB, et al, conducted at department of pharmacology, M P Shah Medical College, Jamnagar observed polypharmacy in their respective regions in which the average no of antibiotics use was $9.2 .^{13}$

The average number of drug per prescription is a valuable indicator of polypharmacy, it is recommended that the number of drugs per prescription should be kept as low as possible to minimize the rise of drug interaction, adverse drug reaction.

In the present study, all antibiotics which is prescribed to the patients were included in the National essential drug list.

We have also studied on distribution of antibiotics according to class out of 100 patients included for study in $86(86 \%)$ patients were prescribed with cephalosporins, 15 $(15 \%)$ patients were prescribed Fluoroquinolones, 64 (64\%) patients were prescribed with aminoglycosides, 53 (53\%) patients were prescribed with Penicillins 19 (19\%) patients were prescribed with antiameobiasis. This study is similar to Venkateswarlu B, et al, Higher utilization of cephalosporins $80.5 \%$ and fluoroquinolones $38 \%$ was noticed. ${ }^{11}$

Higher utilization of cephalosporins 86 (86\%) and aminoglycosides 64 (64\%) was noticed Cephalosporins are commonly prescribed due to their relatively lower toxicity and broader spectrum activity. Cephalosporins often used in combination with aminoglycosides due synergistic activity and broader coverage of organisms for several serious gram negative infections $30(30 \%)$ patients were prescribed pencillins with aminoglycosides, 10 $(10 \%)$ patients were prescribed with nitroimidazole antibiotics.

The duration of treatment in hospital was $52(52 \%)$ patients had duration of treatment was 5 days or less than 5 days, $48(48 \%)$ patients had duration of treatment was more than 5 days, ranges was 3-10 days mean duration recorded was 5.5 days, this study is differ from a study by Bhansali NB et al, conducted at department of pharmacology, M P Shah Medical College, Jamnagar in which mean duration of postoperative stay in was 8.77 
days and a range of 4-15 days and similar to study conducted by Rasheeduddin $\mathrm{M}$ et al, conducted at Adilabad Telangana State, India which total duration of treatment ranges was 5 -12 days mean duration was recorded 9.2 days. ${ }^{13,14}$

In our study the most common antibiotic prescribed was ceftriaxone $38 \%$ a third generation cephalosporins with restricted prescription followed by Injamoxicillin+clavulanicacid 18\%, Inj-amikacin $69 \%$, Inj ceftriaxone+sulbactum $7 \%$, Inj-ceftriaxone+tazobactum $10 \%$, Inj-ampicillin $25 \%$, Inj-metronidazole $10 \%$, Injciprofloxacin $2 \%, \quad$ Inj-gentamycin $2 \%, \quad \mathrm{Tab}$ amoxicillin+clavulanicacid $\quad 40 \%, \quad$ Tabcefixime+clavulanic acid $28 \%$, Tab-Cefixime $3 \%$, TabCefopodoxime clavulanicacid 23\%, Tab-levofloxacin $14 \%$, Tab azithromycin 1\%, Tab-clinadamycin $2 \%$. Compared to another study conducted by Venkateswarlu $\mathrm{B}$, et al, at Malla Reddy Institute of Pharmaceutical Sciences, Secuderabad, Telangana, India. Brethis CS. ${ }^{11,12}$ conducted at Mahavir Institute of Medical Sciences, Hydrebad India. Sviestina I et al, conducted at Public Health and Epidemiology Department, Riga Stradinš University, Dzirciema iela, Riga, Latvia. respectively cefotaxim $51.5 \%$ and ceftriaxone $13.39 \%$ was most commonly prescribed drug. ${ }^{15}$

In our study mean age of the patient was $36.64 \pm 15.9$ years (Mean \pm SD) and the range of ages was between 18-90 years old which is differ from study conducted by Tourmousoglou CE et al, at Department of Pharmacology, Medical School, University of Athens, Athens, Greece found that mean age of the population was $58.8+15.2$ years. ${ }^{16}$

In our study, the $39 \%$ of patients received antibiotic combination (two or more antibiotic) and $18 \%$ of patient received monotherapy of antibiotic. In contrast of our result study conducted by Rehan HS et al, at lady hardinge medical college and SSK hospital, New Delhi India in which $41 \%$ patients received two drug, $28 \%$ received one drug antibiotic remaining $19 \%$ patients received three drugs and 1 patient received 4 drugs for prophylaxis while in another study conducted by Brethis CS et al, conducted at Mahavir Institute of Medical Sciences, Hydrebad India. ${ }^{12,17}$ In which $12.6 \%$ of the patient prescribed with monotherapy remaining $87.4 \%$ were received more than two antibiotic combination.

$86 \%$ prescriptions had antimicrobial agents that were included in the WHO Essential drug list and only $14 \%$ of prescriptions contained drugs that were not included in the WHO Essential drug list. ${ }^{18} 100 \%$ prescription had antimicrobial agent that were included in National list of essential medicine, similar to a study by Brethis CS et al, conducted at Mahavir Institute of Medical Sciences, Hyderabad, India in which $86.4 \%$ prescriptions had antimicrobial agents that were included in the WHO Essential drug list and only $13.6 \%$ of prescriptions contained drugs that were not included in the WHO Essential drug list. ${ }^{12,19}$

\section{CONCLUSION}

Antibiotics are a key component of infection management and prevention. In conclusion, a wide spectrum of clinical diagnosis and a variety of drugs were prescribe from various drugs classes.

The overall scenario of antibiotic usage in a Hospital was as per standard recommendations and all the antibiotics used were according to their standard adult and titrated doses and frequencies. In this study we found that Cephalosporines, Penicillins, Aminoglycosides and Nitroimidazole were mostly used classes of drug. Adverse Drug Reactions were minor and well managed. However, use of culture and sensitivity and more strict prescription pattern should be followed in order to overcome the bacterial antibiotic resistance which is a potential threat for use of antibiotics.

Our study suggests that there is a considerable scope for improving prescribing pattern among the practitioners and minimizing the use of antibiotics in order to reduce the risk of antibiotics resistance.

Funding: No funding sources

Conflict of interest: None declared

Ethical approval: The study was approved by the Institutional Ethics Committee

\section{REFERENCES}

1. Sathvik BS. Drug utilization evaluation in parthasarthi G, Nyfort-Hansen K, Nahata Mc, A Textbook of Clinical Pharmacy Practice. $1^{\text {st }}$ Ed, Orient Longman India; 2004:362-375.

2. Bergman U, Popa C, Tomson Y, Wettermark B, Einarson TR, Åberg H, et al. Drug utilization 90\%-a simple method for assessing the quality of drug prescribing. European Journal of Clinical Pharmacology. 1998 Apr 12;54(2):113-8.

3. Kollef $\mathrm{MH}$. Optimizing antibiotic therapy in the intensive care unit setting. Critical Care medicine. 2001;5:189-95.

4. Niederman MS. Appropriate use of antimicrobial agents challenges and strategies for improvement. Critical Care Medicine. 2003;31:608-16.

5. Carlet J. Epidemiology and control of antibiotic resistance in the intensive care unit. Current Opinion in Infectious Disease. 2004;17:309-16.

6. Rønning M, Salvesen Blix H, Tange Harbø B, Strøm H. Different versions of the anatomical therapeutic chemical classification system and the defined daily dose-are drug utilisation data comparable?. European journal of clinical pharmacology. 2000 Dec $1 ; 56(9): 723-7$. 
7. Hess RD. Retrospective studies and chart reviews respiratory care. Journal of Pharmacy. 2004;49:11714.

8. McGowan JE. Antimicrobial resistance in hospital microorganisms related to antibiotic use. Bulletin of the New York Academy of Medicine. 1987;63(3):25368.

9. Tamma PD, Cosgrove SE. Antimicrobial stewardship. Infectious Disease Clinics of North America. 2011;25(1):245-60.

10. Napolitano F, Maria T. Evaluation of the appropriate antibiotic prophylaxis. Plos One Journal. 2013;11(8):532-9.

11. Venkateswarlu B, Swapna. Drug utilization study of antibiotics in surgical ward of a tertiary care hospital. International Journal of Chemical and Pharmaceutical Sciences. 2015;6(1):1-7.

12. Brethis CS, Thamizharasan S. A prospective study of the pattern of use of antimicrobial agents in surgical prophylaxis in a tertiary care centre. International Journal of Pharmacy and Pharmaceutical Sciences. 2017;9(1):1-5.

13. Bhansali NB. Drug utilization study in post-operative patients in surgical ward of a tertiary hospital attached with medical college. Scholars Research Library. 2013;5(1):251-7.
14. Rasheeduddin Mohd, Shankar Ravi B, Babu JN. Antibiotic Utilization Study in the Department of Surgery. Scholars Journal of Applied Medical Sciences. 2016;4(8):2918-23.

15. Sviestina I, Mozgis D. Evaluation of the Antibiotic Use for Surgical Prophylaxis in Pediatric Acute Appendicitis. Journal of Young Pharmacists. 2015;7(1):150-5

16. Tourmousoglou CE. Adherence to guidelines for antibiotic prophylaxis in general surgery. Journal of Antimicrobial Chemotherapy. 2008;61:214-8.

17. Rehan HS, Kakkar AK. Surgical antibiotic prophylaxis. International Journal Infection Control. 2010;6(2):130-4.

18. The selection and use of Essential medicines. Report of 19th WHO expert committee. WHO Technical Report Series. 2014;985:114-7.

19. The selection and use of Essential medicines. National list of essential medicines (NLEM). 2015;32:1-38.

Cite this article as: Joshi DK, Mohd R, Kothiyal P, Joshi Y. Evaluation of prescription pattern of antibiotics for surgical prophylaxis in secondary care hospital. Int J Basic Clin Pharmacol 2017;6:1969-76. 